\title{
Sustainable Design in Space Structures
}

\author{
Dimitra Tzourmakliotou \\ Laboratory of Steel Structures, Department of Civil Engineering, Democritus University of Thrace, Greece
}

\begin{abstract}
The sustainable design approach presented in this paper supports an increased commitment to environmental stewardship and conservation, and results in an optimal balance of cost, environmental, societal, and human benefits while meeting the mission and function of the intended space structure. The aim of this paper is to develop the guidelines that could be applied in the design of a space structure in order to achieve the optimal overall lifetime performance of the space structure. Space structures are more than inanimate hunks of metal, glass and fabric. Every space structure that we design as structural engineers is like a child — a child that is conceived with a passionate vision of its form, structure and purpose; nurtured through the schematic design phase and the development of construction documents; and cared for during the labor pains of plan check corrections, requests for information, shop drawing review, and construction observation. Like children, our space structures mature, perform necessary functions during their lives, and eventually, grow old and die. The design of a sustainable space structure is a much more challenging and cross-disciplinary process than in the past and therefore it is necessary that the space structure is viewed as an integrated system and that all members of the design team work in a fully integrated fashion.
\end{abstract}

Key words: Sustainable design, integrated life cycle design, space structures.

\section{Introduction}

Technology innovations, population growth, evolving ecology problems, changing economies and life styles are imposing new requirements on a built environment. This has an influence considerably upon the way we ought to design and build in the future. The most important issue regarding the space structure today is related to the increase of its environmental efficiency which can be achieved by creating the potentials for closed loop material cycling of building products. One of crucial problems of today's space structure construction is that space structures are made in such a way that many alterations lead to demolition of their parts or even whole structure. The main reason for this is the fact that different functions and materials comprising a building system are integrated in one closed and dependent structure which does not allow alterations. This is one of reasons for immense waste accumulation. In order to improve environmental

Corresponding author: Dimitra Tzourmakliotou, PhD, assistant professor, research fields: steel structures, space structures.E-mail: dimitratz@gmail.com. efficiency of the space structure we need to change our perception of the space structure's design and its technical composition.

The importance of approaching each space structure holistically from the outset cannot be understated. From the space structure's inception, architectural teams must work closely with structural and Mechanical, Electrical and Plumbing (MEP) engineers, landscape designers, urban planners and the entire project team to ensure that each element of a space structure's design complements and supports the performance of other elements and building systems. This is especially critical from the standpoint of sustainability [1]. To achieve maximum energy independence, support healthier lifestyles and respond to the changing needs of the planet, space structures must be designed with a strong understanding of their environmental context. If they can achieve a symbiotic relationship with their environmental context, they can make the best latent value of their site and take steps towards generating natural, environmentally friendly energy [2]. 
Unfortunately, the typical design process, as practiced with current codes, is incapable of providing the vehicle with which architects, engineers, and building owners can consider a space structure's true life-span and control the performance that the space structure experiences during its existence. Building codes arbitrarily assign a design life of 50 years to space structures - a life span that is clearly insufficient for most space structures. In addition, current structural design practice does not allow for the future structural modifications that are required to provide buildings with the ability to grow in a changing world and adapt to advances in technology and our improved understanding. As a result, the space structures we design today could become extinct during our lifetimes and turn into behemoths of a past age that are incapable of meeting the future needs of our communities. In order to respond effectively the entire design process should be altered.

\section{Design}

During the design phase of a space structure, the structural engineer may affect the sustainability of a project through

(1) the choice of locally available resources,

(2) the recyclability and reusability of materials and systems,

(3) the efficiency of structural systems, and

(4) informed choices about demolition and preservation.

Resource location is a determining factor in material choice. Local resources minimize the use of fossil fuels in truck transportation and potentially increase the efficiency of the building process. The structural engineer should be aware of locally available materials, and make efforts to design using these materials. These materials would ideally be both harvested and manufactured in the local area. During construction, using local materials can result in shorter lead times, which can simplify logistics and speed up the construction process.
Choices concerning labor resources should be made similarly, though in fact the structural engineer often has little influence in contractor selection. For many of the same reasons as with material selection, a project's overall sustainability will benefit when contractors and labor pools are in close proximity to the project location. Similar to procuring materials from manufacturers within a local radius, a goal should be also made to work with contractors and subcontractors within a certain radius. Advantages of this include expertise on the local climate of the labor market, knowledge of local suppliers and manufacturers, and minimization of fossil fuels in daily transportation to the site. All these decisions about local materials and labor must be balanced with decisions of availability, cost, scheduling and appropriateness for the project as a whole [3].

The choice of the structural system during the design phase is another factor that affects the sustainability of a project. For both the gravity and lateral force resisting systems, the engineer has a choice of materials, which include steel, fabric, glass, wood, and concrete. Often, the use of different materials to optimize the performance of each is the best solution. For example, steel cables can be extremely efficient tension members of a wood truss. Wood truss members can be supported by concrete walls and open web steel joists which can be supported by wood shear walls. Taking advantage of the inherent properties of the material can result in a reduction of the amount of material. Lateral force-resisting systems have similar concerns. Various systems are appropriate for different scales, loads, functions, architectural requirements, and seismic performance levels. The efficiency and sustainability of the material chosen for the system, the various types of systems available for a given material, and the desired performance level must be determined. Some factors affecting material choice include weight per square meter, reusability, recyclability, deconstruction, and $\mathrm{CO}_{2}$ emissions associated with the production and installation of the material, as well as all the traditional 
factors such as cost and performance. A lateral system designed for a higher level than basic code requirements may cost more initially. However, during a seismic event, the structure will likely perform better and could save materials and labor by minimizing repairs, or in the worse case, avoiding demolition. In addition, time and cost savings can also be achieved since the space structure will be less disrupted for repair or rebuilding after an earthquake. In order to fully consider sustainability in the design process, options other than demolition at the end of a space structure's useful life should be considered in design. Though an owner or architect would primarily make this decision, the engineer can facilitate this process by providing options for adaptability of the structure for other uses or deconstruction. The condition of the structure is often not the determining factor for when a space structure is no longer useful. Adapting a space structure for other uses will conserve resources associated with demolition and reconstruction and also eliminate construction waste. To ensure that a structure can last into future space structure uses, it must to be designed for durability in a seismic environment or any other natural hazards to which it may be subjected [4].

The structural engineer's choice of structural systems during the design phase also affects how a space structure can be adapted for a future use. Space structures may change use over their lifetime, and therefore require reconfiguration of its elements. Deliberate placement of structure can integrate with the mechanical systems, openings for light and natural ventilation, all which allow for an energy efficient space structure even with changes of occupants and uses over time. In seismic regions, a space structure may not be readily adaptable due to seismic deficiencies. However, the benefits of users adaptability are the same as those associated with seismic rehabilitation of a structure. When adaptability is not an option, deconstruction is the next best alternative to demolition. The goals of deconstruction are not only to design for ease of disassembling the structure but also for the members to be reused in other structures. Modifying and reusing members consumes less energy than recycling. Lastly, recycling is still an option if the space structure or its members cannot be reused [5].

\section{Benefits of Sustainable Design}

Sustainable design strategies bring many benefits, which are often the result of applying common sense to a particular situation [6]:

(1) Astute site selection and appropriate structures minimize intrusion on ecologically sensitive terrain such as wetlands, agricultural lands, flood plains, wildlife habitats, or green spaces.

(2) Passive design creates a space structure envelope that uses natural systems in place of mechanical equipment. For example, sunlight and wind patterns are used to improve internal illumination and ventilation for occupants while reducing energy consumption.

(3) Computerized space structure models help designers predict and compare the interactions and performances of alternative designs and systems, informing their equipment choices and leading to an integration of technologies with natural systems to create a high-performance space structure.

(4) Space structure owners save costs. Reduced reliance on mechanical systems lowers capital costs, while reduced water and energy consumption cut utility bills. Often, a better designed envelope does not cost more than conventional designs, and any increase is almost always more than compensated for by operational savings over the lifetime of the building - a lifetime that is extended by design choices that maximize durability and adaptability.

(5) Space structure occupants breathe fresher, cleaner air, and work in spaces that are well lit and very adjustable to their personal preferences.

(6) The surrounding community benefits from less loading of municipal transportation, electricity, 
sewerage, and solid waste infrastructure, as well as from a site development that preserves ecologically sensitive areas and sets out to be a harmonious neighbor in every way.

\section{The 3R's Reduce Reuse Recycle}

Reduce, reuse and recycle are the three essential principles of sustainable design. They refer to practices that conserve primary resources, reduce waste, and, if incorporated in the space structure design, reduce the overall environmental impacts of a space structure. They also encourage economic connections and opportunities in the community [7]. The three principles are presented in order of their effectiveness in theory: it is better to use less of something than to deal with the byproducts; it is better to reuse something in its original form than to require it to be processed by recycling.

\subsection{Reduce}

The first principle is the easiest to understand because it simply means to conserve, to use less to begin with. When brought into practice, the reduction principle can cut waste, hauling and disposal fees, and project capital costs. There are several ways of design that professionals can apply the reduction principle to design and construction practices:

(1) Carefully calculate the quantity of materials required for a project. This simple step can reduce the amount of materials purchased and wasted on site.

(2) Avoid selecting products that have excessive packaging. Designers can ask suppliers to minimize product packaging or to take back packaging for recycling, reducing on-site waste.

(3) Select more durable materials which will need repair and replacement less often.

(4) Ensure proper on-site storage and protection of materials. This practice can minimize damage to material and reduce the need to purchase more materials.

\subsection{Reuse}

The reuse principle mandates that materials be utilized again in their original form wherever possible, making more intensive use of existing materials. By reusing materials, designers extend the useful life of a material and reduce the amount of waste generated on-site and sent to local landfills. This is particularly important for the construction and demolition industries, which generate large waste streams that are typically composed of reusable materials.

Designers can increase a material or product's lifespan by designing for its disassembly. This technique facilitates the maintenance and repair of materials, the reuse of parts and components, and the recovery of reusable building materials. Salvaging material also helps preserve high quality workmanship or historical or cultural materials that are difficult to replicate or hard to find. This principle is applied in sustainable design and construction practices by:

(1) Reusing building materials on construction and renovation sites.

(2) Salvaging materials prior to demolition for reuse on-site or resale to used building material stores.

(3) Retrofitting an existing space structures instead of constructing a new space structure.

(4) Relocating an entire space structure that would otherwise be demolished.

(5) Designing space structures to be disassembled, encouraging material salvage and reuse. This focuses attention on making materials easy to unfasten or disconnect.

Moreover, there are three different scenarios that can be found in the reuse principle as are referred below.

\subsubsection{Whole Space Structure Reuse}

The first scenario is that of relocation or reuse of an entire space structure. This may occur where a space structure is needed for a limited time period but can later be reused elsewhere for the same or similar purpose. A good example of this is the Crystal Palace of 1851. This modular exhibition building designed by Joseph Paxton was based on a simple system of 
prefabricated structural and cladding units that could be easily joined together. These factory produced elements allowed for the quick assembly and disassembly of the building, and its eventual relocation and reuse after the exhibition [8].

\subsubsection{Component Reuse}

The second scenario is the reuse of components in a new building or elsewhere on the same building. This may include components such as cladding element or internal fit-out elements that are of a standard design. This scenario of reuse saves on resources, waste disposal, and energy use during material processing as well as energy use during component manufacture and transport.

\subsubsection{Material Reuse}

The third scenario that of reprocessing of materials into new components, will involve materials or products still in good condition being used in the manufacture of new space structure components. A good example of this is the re-milling of steel. In most parts of the world that use steel as a building material there is a strong vernacular tradition of constructing space structures so that members may be removed and reused or re-processed into smaller members.

\subsection{Recycle}

When used material is recovered and reprocessed into a new usable form, it is diverted from landfills to become a feedstock for new products. Recycled-content building materials, which contain postconsumer and/or post-industrial feedstock, make more efficient use of existing materials. Sustainable design practices also encourage the diversion and recycling of demolition, land-clearing, and construction debris. Though the energy expenditure associated with recycling makes it the third choice among the three strategies, it is greatly preferable to waste disposal [9]. Design professionals apply the recycle principle by:

(1) Selecting recycled-content building materials and products helps to encourage this emerging environment-friendly industry.
(2) Implementing a job-site recycling plan that separates recyclable materials from non-recyclable materials. For example, clean wood, scrap metal, cardboard, glass, asphalt, concrete and land-clearing waste generated on construction or demolition sites can be easily be separated for recycling.

(3) Designing a storage and collection area for recyclables materials that will be collected during the occupancy of a space structure.

The 3Rs principles, when established at the beginning of a project, help project teams purchase accurate supplies of materials and reduce the amount of construction and demolition of waste generated. The result saves costs and reduces environmental impacts. It also sets an example for conserving natural resources and reducing the broader environmental impacts associated with the extraction, manufacturing, and transportation of building materials. Sustainable design principles and strategies depend on the quality of the components available and the systems assembled to implement them. Designs are realized by creating systems of components that work together to satisfy occupants while minimizing environmental impacts and resource use.

\section{Construction}

Decisions that the structural engineer makes during the design phase affect resource conservation during the construction process and the end of a space structure's useful life. In order to be better informed about the decisions affecting sustainability, the structural engineer and the entire design team can benefit from a contractor's input and owner involvement during the design process. The contractor is often more informed of material availability and recyclability than the rest of the design team. The contractor can inform the design team of typical dimensions and size of materials that can affect design decisions. This may add an additional upfront cost, but over the duration of the project can provide a more streamlined process and end result, and therefore minimizes cost. 
Another factor that affects the construction process is the use of prefabricated elements, and the efficiency is even greater if a single unit type can be used repetitively in a project. Because prefabrication is typically done offsite in a shop under controlled conditions, it is easier to obtain more precise elements and a therefore a more efficient use of materials. Cost and material efficiencies are often found through mass production. Also, by producing the elements in a shop's controlled atmosphere, material waste can be better and more easily controlled. Conditions can be established to control dust, noise and air pollution, and therefore minimize it on the construction site. These factors likely decrease the overall cost as well.

\section{Performance Based Engineering}

The investment of design effort and thoughtfulness in the implementation of sustainable systems of a space structure deserves a corresponding amount of thoughtful design effort and owner investment in the structural system of the space structure. If the conscientious intent of sustainable design includes conserving operating costs and resources in the space structure and maintaining and prolonging the useful life of the space structure, then the design approach should extend beyond the space structure shell to the space structure contents as well. The space structure and its contents together comprise the sustainable design system. The consequences of the structural performance on the space structure contents and systems should be considered because the building performance can protect and prolong the benefits of the sustainable systems and of the other investments that the owner has committed to. The selection of a structural system for a space structure has direct consequences when that system is tested during an earthquake. The performance of the structural system is manifest in the level of damage after the earthquake. With the constant cyclic development of our engineering knowledge that incorporates observed damage from earthquakes and the implementation into practice, there is typically a predictable damage scenario that can be portrayed if the structural system, space structure type, contents, and cladding system are known. The intent of the code is to provide "life-safety", and does not preclude damage. The damage has a cost associated with it. If the damage is to be repaired, the repair effort uses resources in the form of labor, raw materials, and business resources that are suspended or redirected. If the damage is extensive enough that repair is not pursued, then resources are used to dismantle the space structure, and the space structure components are hauled away to landfill.

There is a negative financial impact with damage. If there is damage to the space structure and its contents, then the owner can lose initial advantages of any sustainable design decisions if there is significant value of earthquake damage. Other losses are in the downtime of the business, as well as in the efforts afterwards to recoup damage, such as creating duplicate functions to cover the losses until the damaged portion is repaired. The recovery efforts have physical and time components: repair and recovery of the physical plant as well as recovery of the interruption of business.

In order to avoid these negative cost and time scenarios, structural systems can be selected using a performance based design method, as informed by interaction with site characteristics. In the evaluation of different systems, the interaction of the site, space structure shell, and space structure contents should be considered. Life cycle cost implications should also be evaluated [10]. The initial cost of implementing a structural system should be considered with respect to the value of the sustainable design components, the savings in operating costs, damage prevention, and the prolonged life of the space structure.

Performance considerations of a structural system can have different criteria, depending on the function and objectives set out for the space structures. Good performance can be one where damage to the space structures shell and contents is minimized if the intent 
of the design is to have the space structure as intact and functioning soon after a seismic event. For another type of space structures and set of objectives, a measure of acceptable performance may be more extensive damage, but the damage is controlled. Evaluating and choosing a structural system for either scenario involves the same process of evaluating and balancing considerations in a probabilistic risk and cost analysis that includes performance metrics, performance for different seismic levels, initial first cost, cost of repair or reengagement of the space structure system.

\section{Conclusions}

In order to design truly sustainable space structures, it is necessary that all members of the design team work in a fully integrated fashion and that the space structure be viewed as an integrated system. Individual space structure systems no longer exist independent of each other but are increasingly heavily linked across disciplines. The structural elements are required to form both architectural, mechanical heating and cooling functions, and lighting.

This makes the design of a sustainable space structure a much more challenging and cross-disciplinary process than in the past. Changes or problems in one discipline cannot be readily rectified or instituted without impacting the other disciplines, which are now linked together in ways never before undertaken in space structure design. New computer design tools such as energy modeling and building information modeling will provide even more incentive and the capability to work in fully integrated design teams to create more environmentally sound, high performance space structures.

\section{Acknowledgments}

The authors wish to thank Dr. Xiao Xin of the Department of Mechanical and Nuclear Engineering at Kansas State University for help during different stages of the FE simulation. They would also like to thank Mr. Paul Lewis of Kansas State University, who helped during curling data collection.

\section{References}

[1] A. Sarja, Integrated Life Cycle Design of Structures: Spoon Press, 2002.

[2] S. Brand, How Buildings Learn: What Happens after They're Built, Penguin Group, 1994.

[3] E. Durmisevic and J. Brouwer, Design aspects of decomposable building structures, in: Proceedings of CIB 272, TG 39, Germany, 2002, pp. 81-103.

[4] F. Doyle, Design for Deconstruction, Architectural Review Australia, 1994, pp. 86-90.

[5] P. Crowther, Developing guidelines for design for deconstruction, in: Proc. of the Deconstruction Closing the Loop conference, BRE, Watford, UK, 2000.

[6] B. Guy, Building deconstruction assessment tool, in: Proc. of the Deconstruction and Materials Reuse: Technology, Economic, and Policy, 2001, CIB 266, pp. 125-136.

[7] S. L. Fletcher, O. Popovic and R. Plank, Designing for future reuse and recycling, in: Proc. of the Deconstruction - Closing the Loop Conference, BRE, Watford, UK, 2000.

[8] T. F. Peters, Building the Nineteenth Century, MIT Press, Cambridge, 1996.

[9] W. Addis and J. Schouten, Principles of Design for Deconstruction to Facilitate Reuse and Recycling, CIRIA, 2004.

[10] S. L. Fletcher, O. Popovic and R. Plank, Layered life cycle approach to building design, in K. Steemers and S.Yanos (Eds.): Architecture City Environment: Proc. of PLEA, Cambridge, UK, 2000, pp. 725-730. 